\title{
Ghrelin-producing epsilon cells in the developing and adult human pancreas
}

\author{
K. M. Andralojc • A. Mercalli • K. W. Nowak • \\ L. Albarello • R. Calcagno $\cdot$ L. Luzi $\cdot$ E. Bonifacio • \\ C. Doglioni $\cdot$ L. Piemonti
}

Received: 30 June 2008 / Accepted: 14 November 2008 / Published online: 19 December 2008

(C) Springer-Verlag 2008

\begin{abstract}
Aims/hypothesis While the mechanisms of specification and the reciprocal relationships of the four types of endocrine cell (alpha, beta, delta and pancreatic polypeptide cells) within the human endocrine pancreas are well described in adults
\end{abstract}

Electronic supplementary material The online version of this article (doi:10.1007/s00125-008-1238-y) contains supplementary material, which is available to authorised users.

\section{K. M. Andralojc $\cdot$ K. W. Nowak}

Department of Animal Physiology and Biochemistry,

Poznan University of Life Sciences,

Poznan, Poland

A. Mercalli $\cdot$ L. Piemonti $(\bowtie)$

Diabetes Research Institute (HSR-DRI),

San Raffaele Scientific Institute,

Via Olgettina 60,

20132 Milano, Italy

e-mail: piemonti.lorenzo@hsr.it

L. Albarello $\cdot$ R. Calcagno $\cdot$ C. Doglioni

Department of Human Pathology,

Vita-Salute San Raffaele University,

Milano, Italy

L. Luzi

Unit of Nutrition and Metabolism, Department of Medicine,

San Raffaele Scientific Institute,

Milano, Italy

L. Luzi

Physical Exercise for Health and Wellness Center,

University of Milano,

Milano, Italy

\section{E. Bonifacio}

Dresden University of Technology,

Center for Regenerative Therapies Dresden,

Dresden, Germany and during fetal development, ghrelin-immunoreactive cells (epsilon cells) remain poorly understood.

Methods We studied epsilon cells in 24 human fetal pancreases between 11 and 39 weeks of development and in 32 pancreases from adult organ donors.

Results We observed single epsilon cells scattered in primitive exocrine tissue from gestational week 13 in developing pancreas. Later in the developmental process, epsilon cells started to aggregate into clusters. From gestational week 21, epsilon cells were observed located around developing islets, forming an almost continuous layer at the peripheral rim of the islets. They remain localised on the mantle of the islets, although at different amounts, in the adult pancreas. Coproduction of ghrelin with insulin, glucagon or somatostatin was not detected during fetal development. Co-production with pancreatic polypeptide was evident sporadically. Epsilon cells co-produced NK2 homeobox 2 and ISL LIM homeobox 1, but not NK6 homeobox 1 and paired box 6. A quantitative analysis was performed in the adult pancreas: there was an average of $1.17+1.17$ epsilon cells per islet, the relative epsilon cell volume was $0.14+0.16 \%$ and the epsilon cell mass was $0.13+0.15 \mathrm{~g}$. Neither sex nor age affected the epsilon cell mass, although there was a significant inverse correlation with BMI.

Conclusions/interpretation During fetal development epsilon cells show an ontogenetic and morphogenetic pattern that is distinct from that of alpha and beta cells.

Keywords Co-production · Development · Endocrine · Fetal pancreas · Ghrelin · Insulin · Transcription factors
Abbreviations
ISL1 ISL LIM homeobox 1
NKX2-2 NK2 homeobox 2
NKX6-1 NK6 homeobox 1 
PAX6 Paired box 6

PP Pancreatic polypeptide

\section{Introduction}

The pancreatic islets are comprised of four major endocrine cell types that produce the hormones necessary for maintaining appropriate levels of circulating glucose. The alpha cells synthesise glucagon, beta cells synthesise insulin, delta cells synthesise somatostatin and pancreatic polypeptide (PP) cells synthesise PP [1-3]. A few years ago, a fifth mammalian islet cell type, the ghrelin-producing epsilon cell, was described $[4,5]$.

To date, knowledge of the epsilon cell is largely derived from studies on rodents, in which gene regulation can be widely manipulated to provide information about signalling pathways and cell lineages [6]. From these studies we know that epsilon cells can be detected in the mouse pancreas as early as embryonic day 10.5 and are the major source of ghrelin during fetal life [7]. The number of epsilon cells increases during fetal development, and close to birth they begin to localise at the periphery of the developing islets [4, 5]. Generally, the number of epsilon cells is increased in mouse models of beta cell deficiency. In fact, it has been shown that the loss of functional Nkx2-2 [5, 8], Pax6 [9] and Pax4 [10] produces an overabundance of epsilon cells in the pancreas. The origin of epsilon cells in the rodent and human pancreas remains controversial. Ghrelin has variably been reported to be present in alpha cells in rats and humans [11], in beta cells in humans [12] or in separate cell types $[4,13,14]$. In human and rodent pancreases of neonates and adults, a few epsilon cells remain visible in marginal areas of the islets $[4,5,13]$. An insulinostatic function of endogenous ghrelin within islets has been suggested [1517]. In fact, pharmacological, immunological and genetic blockade of ghrelin or ghrelin action in pancreatic islets all markedly enhanced glucose-induced insulin release [15-17].

There is little information on epsilon cells during fetal development of the human pancreas [4]. Like the mouse pancreas, the human pancreas develops from two endodermal diverticula, the dorsal and ventral [1], which fuse at about 56 days of development post coitum [18]. However, the morphogenesis of the endocrine tissue is unlikely to be comparable between species, given the differences in gestation and the larger relative volume of the human pancreas [19]. Extrapolation of rodent-derived knowledge of epsilon cells and pancreatic development to humans is therefore problematic. We investigated the ontogenetic and morphogenetic pattern of epsilon cells during fetal development of the human pancreas. We undertook quantitative and qualitative studies in order to describe ongoing changes in ghrelin production during pancreas development. To understand how epsilon cells are related in lineage to the four classical islet cell types, i.e. alpha, beta, delta and PP cells, we investigated co-production of ghrelin with the main islet hormones (insulin, glucagon, somatostatin, PP) and with transcription factors involved in pancreas development (NK2 homeobox 2 [NKX2-2], NK6 homeobox 1 [NKX6-1], paired box 6 [PAX6], ISL LIM homeobox 1 [ISL1]).

\section{Methods}

Tissue collection and preparation All tissues examined were collected from the surgical pathology department of San Raffaele Hospital (Milan, Italy) according to the rules of the local institutional review boards. Twenty-four wellpreserved pancreatic specimens from fetuses obtained from spontaneous abortion due to maternal causes were used in this study. Tissue preservation was evaluated using histological examination including immunohistochemistry, which showed that staining quality was excellent. In addition to the fetal specimens, we also sectioned a pancreatic block obtained during autopsy of a newborn child $(n=1)$. Sections from the body of the pancreas were obtained from 32 human donor pancreases before islet isolation. Before pancreas digestion, a small piece of tissue was removed from the organ and fixed for quality control. The donors (20 men, 12 women) were $48+13$ years old with a BMI of $25.2+3.3 \mathrm{~kg} / \mathrm{m}^{2}$. The study received ethics committee approval.

Immunocytochemistry Paraffin-embedded tissues were cut into $6 \mu \mathrm{m}$ sections, which were placed on poly-L-lysinecoated slides, dried for $12 \mathrm{~h}$ at $37^{\circ} \mathrm{C}$ and kept at room temperature. The paraffin was removed and the sections rehydrated. Antigenic sites were unmasked by pre-treatment for $3 \times 5 \mathrm{~min}$ in $0.01 \mathrm{~mol} / 1$ citrate buffer $(\mathrm{pH} 6.0)$ in a microwave oven. After cooling at room temperature, the sections were washed in PBS ( $\mathrm{pH}$ 7.4). The slides were then washed in sterile water and incubated for 10 min with $3 \%$ $\mathrm{H}_{2} \mathrm{O}_{2}$ (vol./vol.), for $10 \mathrm{~min}$ with BSA $10 \%$ (wt/vol.), for $1 \mathrm{~h}$ with specific primary antibodies (Table 1), for $30 \mathrm{~min}$ with a biotinylated complex super enhancer (Biogenex, San Ramon, CA, USA) and for $30 \mathrm{~min}$ with an enzyme label (Super Sensitive; Biogenex). Immunoreactivity was revealed using 3,3'-diaminobenzidine as the chromogen (code: K3468; Dako North America, Carpinteria, CA, USA), counterstained with haematoxylin solution (code: 51275; Sigma-Aldrich, Taufkirchen, Germany). The specificity of immunohistochemical staining was checked by omitting either the primary or the secondary antibody, or by using only the chromogen. These tests produced no staining. Since crossreactivity between anti-PP antibody and peptide YY has 
Table 1 Details of antibodies used for immunohistochemistry

\begin{tabular}{lllll}
\hline Antigen & Code & Raised in & Dilution used & Source \\
\hline Ghrelin & SC-10368 & Goat & $1: 2,000$ & Santa Cruz Biotechnology, Santa Cruz, CA, USA \\
Insulin & A0564 & Guinea pig & $1: 100$ & Dako, Carpinteria, CA, USA \\
Glucagon & $4030-01$ & Rabbit & $1: 4$ & Linco Research, St Charles, MO, USA \\
Somatostatin & A566 & Rabbit & $1: 600$ & Dako \\
PP & $7100-0659$ & Rabbit & $1: 400$ & Gentaur, Kampenhout, Belgium \\
PAX6 & AB5409 & Rabbit & $1: 1,500$ & CHEMICON International, Temecula, CA, USA \\
ISL1 & 39.4D5 & Mouse & $1: 200$ & Columbia University, New York, NY, USA \\
NKX2-2 & SC-25404 & Rabbit & $1: 100$ & Santa Cruz Biotechnology \\
Synaptophysin & Ab14692 & Rabbit & $1: 1,200$ & Abcam, Cambridge, UK \\
\hline
\end{tabular}

been reported, control experiments on paraffin sections of human pancreas were carried out to assess the specificity of the labelling obtained with the anti-PP antibodies. For antigen absorption, optimally diluted anti-PP antibody was incubated overnight with excess amounts of PP and peptide YY $(20 \mu \mathrm{g} / \mathrm{ml}$; Sigma-Aldrich). No positive labelling was seen when the sections were incubated with the primary antibodies pre-absorbed with specific antigen PP, whereas a strong reaction was observed in sections incubated with the primary antibody that were pre-incubated with peptide YY.

Double immunocytochemistry This was performed as described above (see Immunocytochemistry) until application of the first chromogen. Sections prepared in this way then underwent another antigen retrieval treatment. No blocking steps were applied during the second staining. The slides were incubated with specific antibodies and staining visualised by first applying biotinylated antibodies, then streptavidin-coupled alkaline phosphatase antibodies, and finally Vector Red as the chromogen (Vector Red Substrate kit, code: SK-5100; Vector Laboratories, Burlingame, CA, USA). The specificity of immunohistochemical staining was checked as described above.

Immunofluorescence Immunofluorescence was performed on paraffin-embedded tissue. Primary antibodies included rabbit anti-glucagon, mouse anti-insulin and goat antighrelin (for details see Table 1), and were used at twice the dilutions used for immunohistochemistry. Secondary antibodies were FITC and tetramethylrhodamine-5-(and 6)isothiocyanate (TRITC) (1:400; Jackson ImmunoResearch, West Grove, PA, USA). Images were obtained with a Leica DM5000 microscope (Leica Microsystems, Wetzlar, Germany), a colour camera (Evolution MP; Leica) and image management software (Leica).

Quantitative analysis All immunoreactive cells were analysed using a Leica DMIRE2 microscope equipped with a colour video camera connected to a computer (Hewlett
Packard, Cernusco sul Naviglio, Italy) and quantified using Axio Vision 4.4 (Carl Zeiss, Oberkochen, Germany). For immunofluorescence, we used a Leica IM50 Image Manager. The ghrelin, insulin and glucagon cell numbers were normalised by the total islet cell number of corresponding islets and expressed as its percentage. Between five (minimum) and 11 islets per case were calculated. Islet size was calculated with the image analysis of single measured islets and expressed as area $\left(\mu \mathrm{m}^{2}\right)$.

The relative beta cell and epsilon cell volumes were calculated by convention as the ratio of beta cell area: exocrine area and epsilon cell area:exocrine area. To measure this ratio, slides immunostained for insulin or ghrelin were analysed using Axio Vision 4.4 software (Carl Zeiss). The slide was scanned using an objective with $\times 4$ magnification. A representative area of pancreas section was chosen for analysis and the coordinates entered into the program. The image analysis quantified total tissue area within this region, followed by the insulin- or ghrelinpositive areas, in order to determine the ratio of hormone staining to total pancreas area. Sensitivity for the hormonepositive areas was high, so all hormone-positive areas were included irrespective of staining intensity. Between 40 (minimum) and 60 fields per case were calculated. Beta cell and epsilon cell mass were calculated using the formula: hormone cell mass=relative hormone cell volume $\times$ pancreas weight. Results are reported as means \pm SD.

\section{Results}

Characterisation of ghrelin-producing epsilon cells during fetal development of the human pancreas We evaluated human fetal pancreas from weeks 13 to 39 of gestational age. A progressive increase in the endocrine cell (synaptophysin-immunoreactive cell) population was evident from the earliest time point (13 weeks), reflecting the progressive expansion of the pancreatic epithelium and an increase in 
the density of endocrine cells within the epithelium (Electronic supplementary material [ESM] Fig. 1). Evidence of formation of endocrine cell clusters was observed with increasing fetal age, especially from 15 weeks onwards, although solitary endocrine cells were still present at all time points. At early time points, endocrine cell clusters generally displayed a homotypic association of either insulin- or glucagon-positive cells. At later time points, heterotypic endocrine cell clustering and the appearance of typical islet-like structures were characteristic. In samples from week 24 until birth we observed localisation of endocrine cells in a way that was typical for mature, adult islets. Thus, the centre of the islet was mainly occupied by insulin-immunoreactive cells, whereas somatostatin- and glucagon-immunoreactive cells were localised on the mantle of the islet and PP cells were rarely present, appearing on the islet periphery (ESM Fig. 2).

We observed single epsilon cells scattered in the primitive exocrine tissue in pancreas obtained as early as week 13 of gestation (Fig. 1). Later (weeks 17-20), epsilon cells started to aggregate into clusters, but unlike insulinand glucagon-reactive cells, which are predominantly localised to clusters at this age (ESM Fig. 3, ESM Fig. 4), epsilon cells were still frequently seen as single cells randomly localised in the surrounding mesenchyme. In pancreas from week 21 and through to late gestation, epsilon cells were located around developing islets, forming an almost continuous layer at the peripheral rim of the islets, with a crescent-like structure. We also observed immunoreactivity for ghrelin in duct cells at all periods investigated.

The percentage of ghrelin-, insulin- and glucagonimmunoreactive cells in islets was evaluated (Fig. 2). We were able to distinguish newly formed islets from gestational week 17. At this time, the average islet size was $998 \pm 418 \mu \mathrm{m}^{2}$. The size increased progressively reaching $13,460 \pm 1,500 \mu \mathrm{m}^{2}$ at birth and $15,321 \pm 1,753 \mu \mathrm{m}^{2}$ in adult life. Epsilon cells in the islets were observed in pancreases from week 21 of gestation. At this time, epsilon cells represented $14.8 \pm 10.2 \%$ of the total islet cell number. The highest percentage was observed in samples from week 23 of gestation $(29.9 \pm 5.8 \%)$. Thereafter, the relative proportion of epsilon cells abruptly decreased until birth $(4.3 \pm$ $1.5 \%$ ), with epsilon cells being rare in adult pancreases $(0.74 \pm 0.5 \%)$. The percentage of insulin-immunoreactive cells in islets was less than $50 \%$ until gestational week 23 (39.2 $\pm 11.1 \%)$, but rose progressively to reach $71.9 \pm 8.6 \%$ in adult pancreases. The percentage of glucagon-immunoreactive cells was about $33 \%$ until gestational week 26 , subsequently decreasing to $24.4 \pm 8.2 \%$ in adult samples.

We did not observe co-localisation of ghrelin with insulin, glucagon or somatostatin at any stage of development (Fig. 3). We did, however, sporadically see occasional co-production of ghrelin with PP in samples from late gestation (ESM Fig. 5). All epsilon cells in fetal pancreas were positive for transcription factor ISL1 (Fig. 4); co-
Fig. 1 Immunohistochemical staining for ghrelin in developing human pancreatic region at indicated weeks of gestation. Beginning from single scattered cells embedded in the primitive pancreas (weeks 13 to 15 ), cells start to aggregate into clusters after week 17 of fetal development. In week 21 ghrelin-positive cells surround primary islets with a cell monolayer. Ghrelinpositive cells are most evident in week 23 , tending in later stages to disaggregate and decrease in number. Scale bars: $25 \mu \mathrm{m}$ for weeks $13-18 ; 100 \mu \mathrm{m}$ for weeks 19 onwards
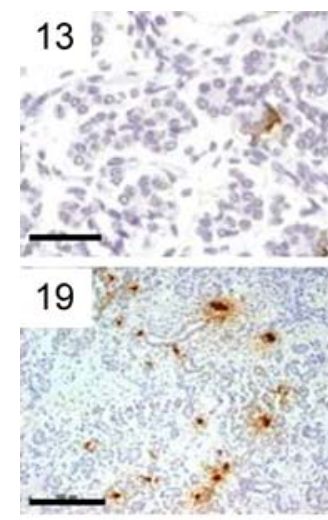

24

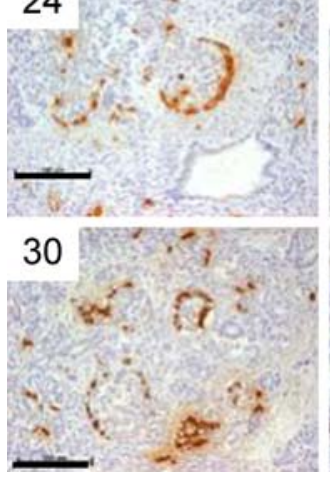

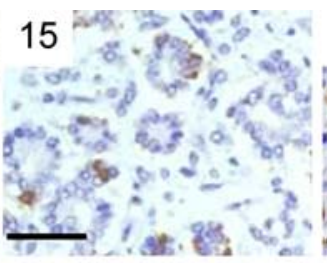
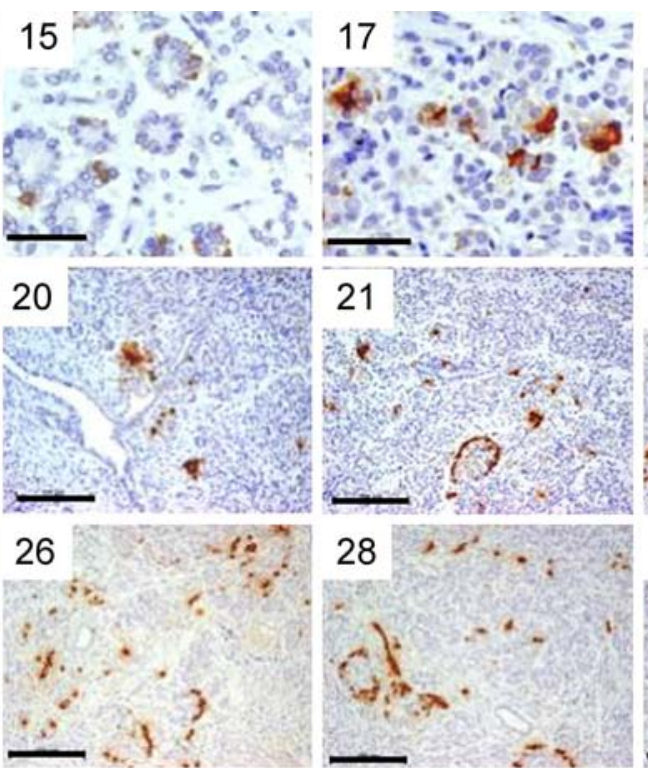

33

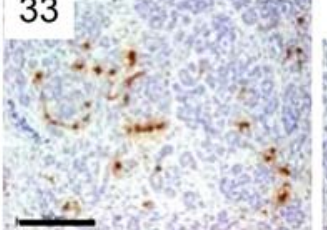

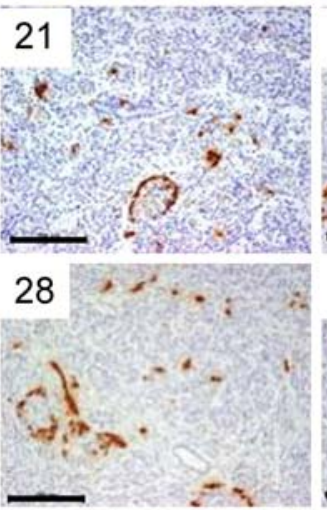

39

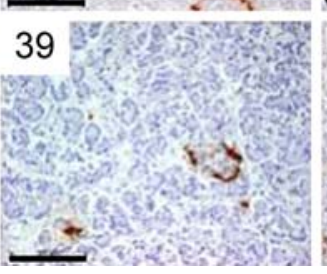

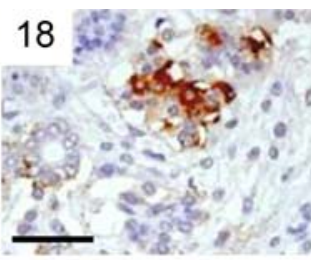
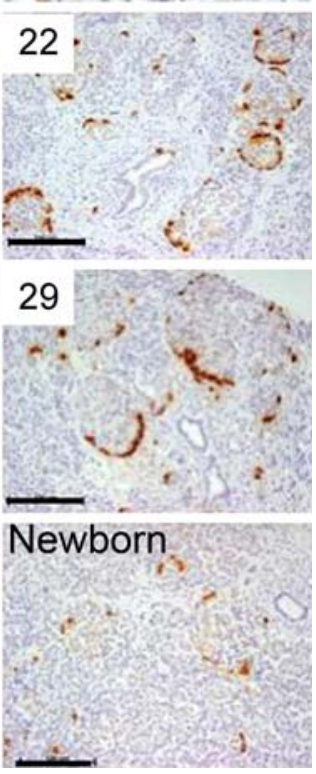


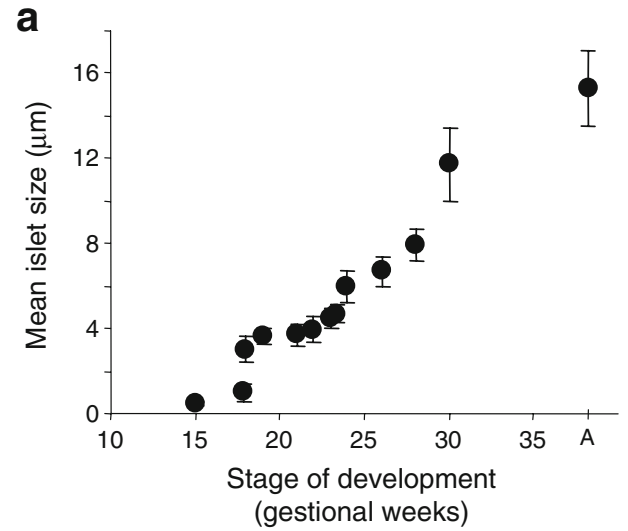

b

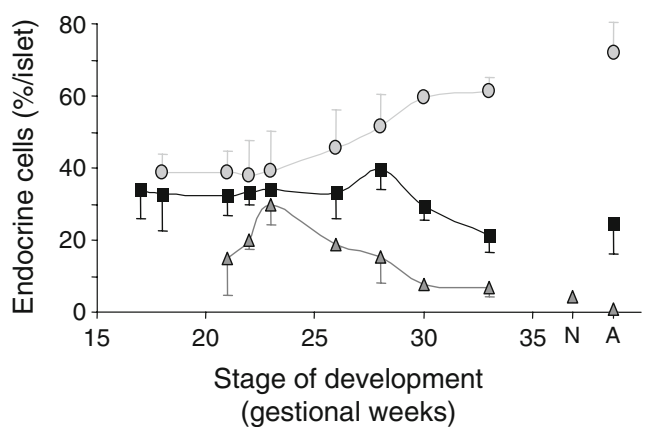

Fig. 2 Dynamics of endocrine mass evolution during human pancreas development. a Islet size during development. Islet size was calculated as area. Calculation was based on five (minimum) to 60 islets each time. b Percentage of islet cells immunoreactive for ghrelin (triangles), insulin (circles) and glucagon (squares) during development. The hormone-positive cell number was normalised by total islet cell number of corresponding islet and expressed as percentage. Calculation was based on five (minimum) to 11 islets each time. Data are expressed as mean \pm SEM. A, adult; $\mathrm{N}$, newborn localisation of ghrelin with NKX2-2 was also observed. We did not detect any co-production of ghrelin with PAX6 or NKX6-1.

Characterisation of ghrelin-producing epsilon cells in adult human pancreas Sections from pancreases were obtained from 32 human donor pancreases and were then used for islet isolation. Epsilon cells were usually round or ovoid in shape and were often located at the periphery of the islets, either as single cells or small clusters of cells. We also occasionally observed immunoreactivity for ghrelin in duct cells (Fig. 5a,b). No co-localisation of ghrelin with insulin or glucagon was observed (Fig. 5c,d).

Analysis of serial sections revealed an average of $1.2+$ 1.2 epsilon cells per islet, with some islets lacking demonstrable ghrelin-immunoreactive cells. The relative beta cell volume (ratio of beta cell area:exocrine area [20]) was $2.5+1.94 \%$. The relative epsilon cell volume (ratio of epsilon cell area:exocrine area) was $0.14+0.16 \%$. As the total pancreas weights were available $(100+21 \mathrm{~g})$, it was possible to estimate the total beta and epsilon cell masses $(2.4+1.9$ and $0.13+0.15 \mathrm{~g}$, respectively). Sex and age did not affect the number of epsilon cells per islet, the relative epsilon cell volume or epsilon cell mass, while a significant inverse correlation with BMI was evident, suggesting a selective loss of pancreatic epsilon cells with an increase in body weight (Fig. 5e-h).

\section{Discussion}

The aim of our study was to investigate the ontogenetic and morphogenetic pattern of epsilon cells during the development of human pancreas. Our findings show that epsilon
Fig. 3 Double immunofluorescence of islet hormones in developing human pancreas. Ghrelin (red) (a, b), insulin (green) (a) and glucagon (green) (b) are shown. Week of gestation are indicated. Original magnification $\times 400$
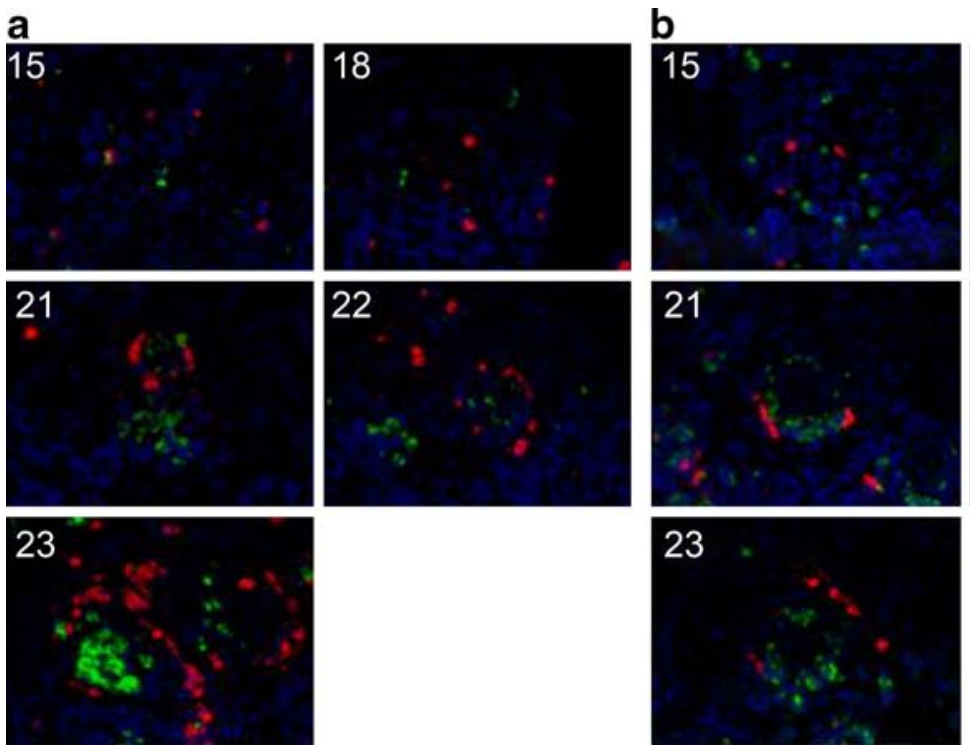
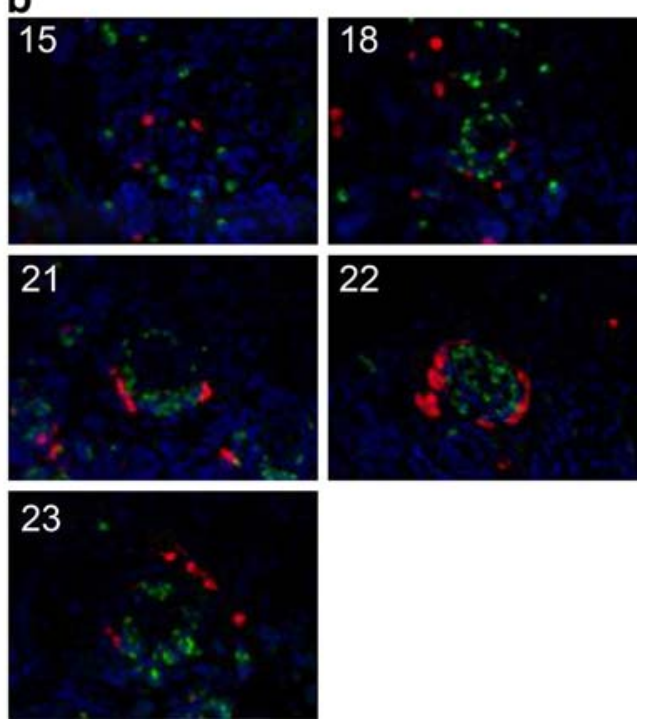
Fig. 4 Ghrelin-immunoreactive cells (red) double-stained with transcription factors (brown) as indicated, at weeks 18, 23 and 30 of development. Scale bars, $100 \mu \mathrm{m}(20 \mu \mathrm{m}$ on insets).

Original magnification $\times 400$

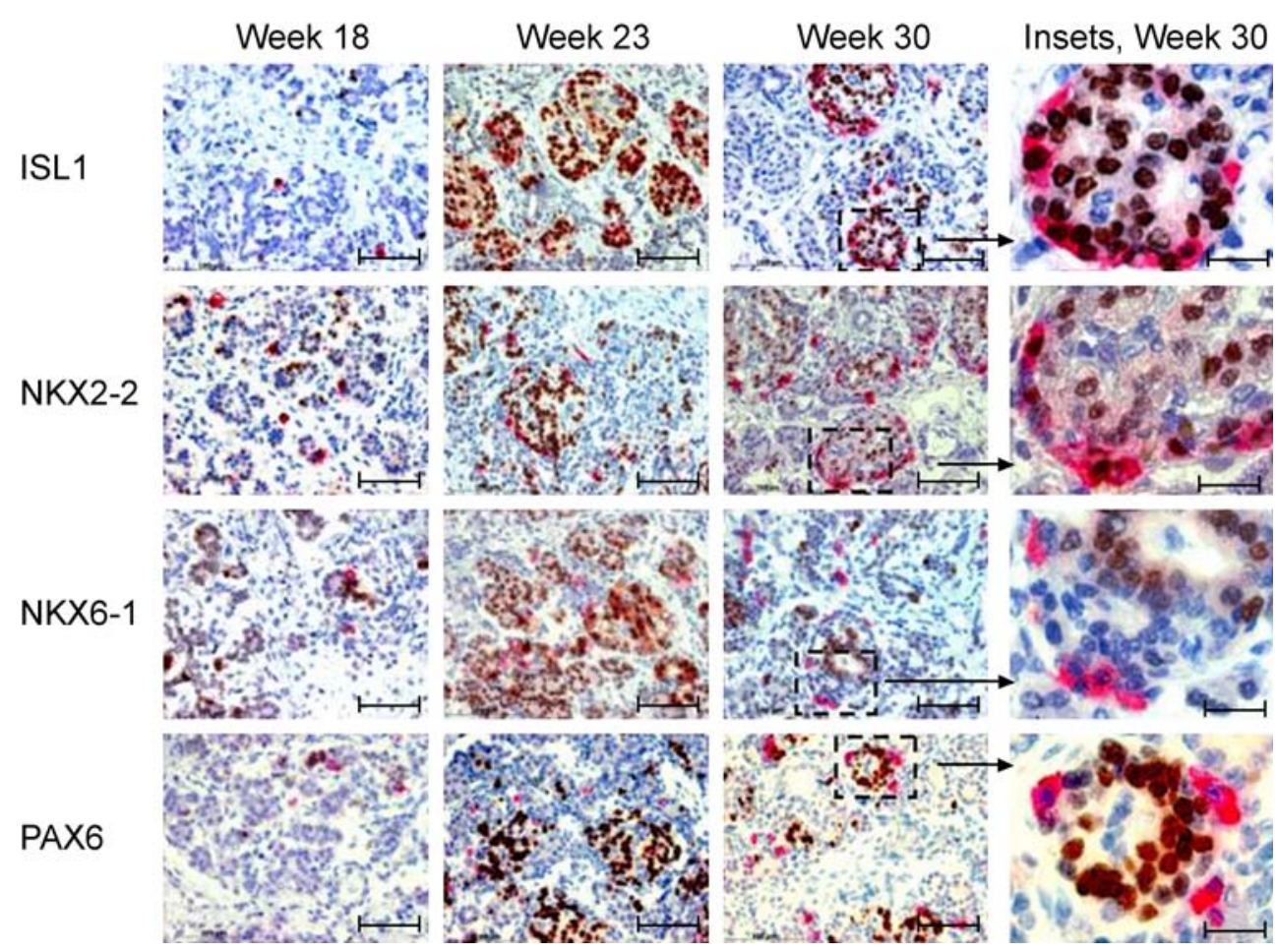

cells have developmental features that are distinct from those of beta and alpha cells.

First, epsilon cells show a distinct change in localisation and number during pancreas development. Wierup et al. reported on the production of ghrelin at human mid-gestation (18-22 weeks) [4] and at adult life, but with a limited number of cases. To date, however, the dynamics of pancreatic ghrelin during fetal life have not been investigated. We have a

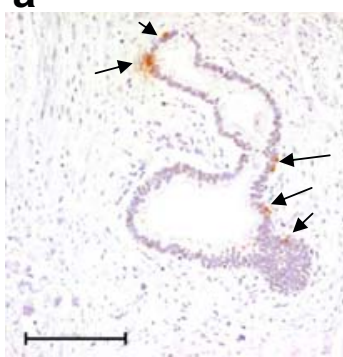

e

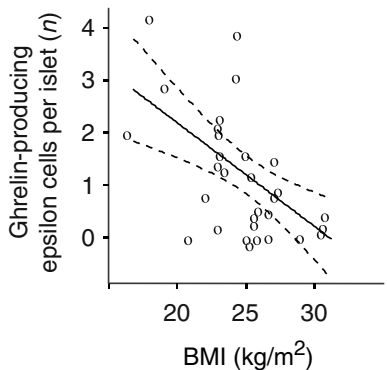

b

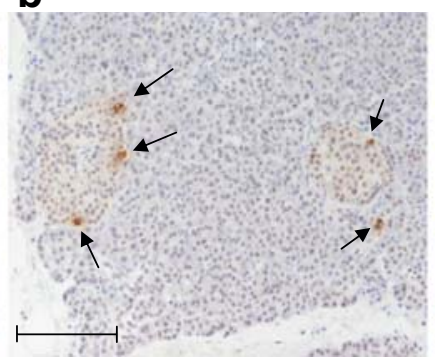

f

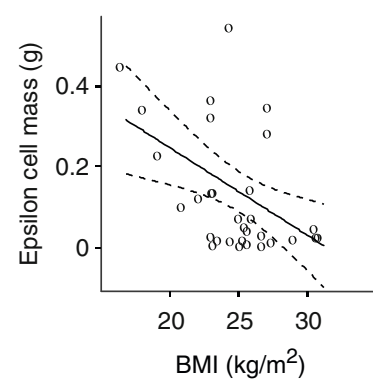

Fig. 5 Ghrelin in adult human pancreas. Immunohistochemical staining of ghrelin-immunoreactive cells in adult pancreas islet (a) and duct (b) (black arrows). Double immunofluorescence of ghrelin (red)/glucagon (green) (c) and ghrelin (green)/insulin (red) (d) in adult human islets. Scale bars, $100 \mu \mathrm{m}$. Original magnification $\times 400$. Ghrelin-producing epsilon cells per islet $(n)(R=0.565 ; p=0.001)(\mathbf{e})$,

C

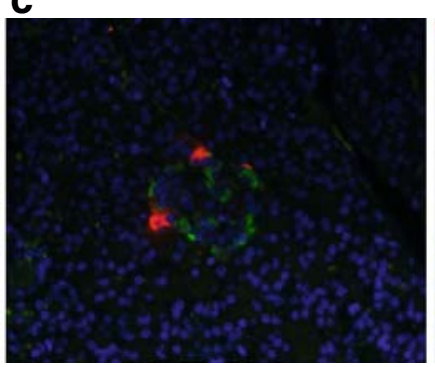

g

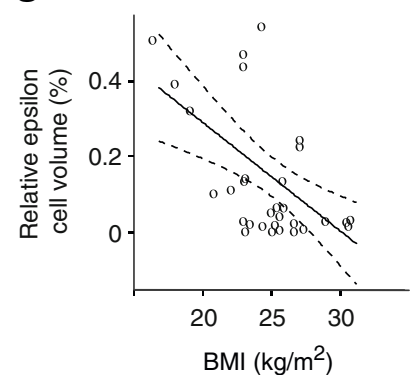

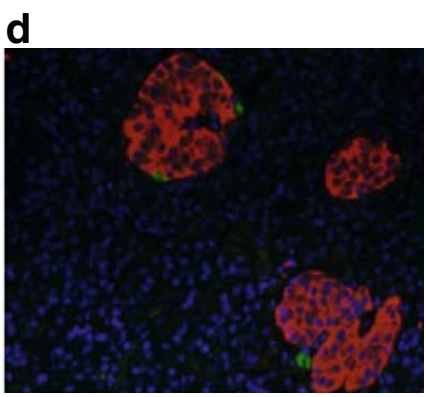

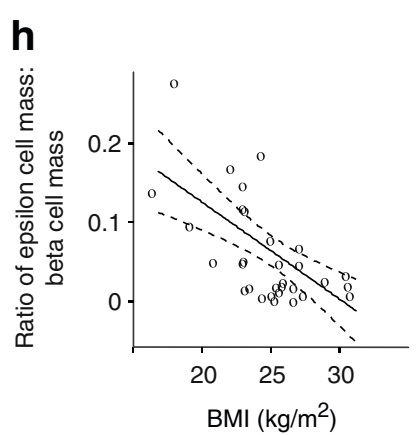

epsilon cell mass $(\mathrm{g})(R=0.482 ; p=0.006)(\mathbf{f})$, relative epsilon cell volume $(\%)(R=0.57 ; p=0.001)(\mathbf{g})$ and ratio of epsilon cell mass:beta cell mass $(R=0.627 ; p<0.001)$ (h) in relation to donor BMI (white circles), $n=32$. Solid line, linear regression; dashed lines, 95\% mean prediction interval 
now shown that epsilon cells remain as single scattered cells in the primitive exocrine tissue until gestational week 21 . At this time, they constitute $15 \%$ of cells in developing islets, reaching $30 \%$ at week 23 and then decreasing to less than 5\% at birth and less than $1 \%$ in the adult pancreas. Of note is the crescent-like pattern of epsilon cells from 21 weeks to birth, suggesting a polarisation phenomenon in developing islets. A potential limitation of the study is that we were able to examine relatively few islets in the pancreas during development, and quantitative results could differ if more or other islets were examined.

Second, epsilon cells do not produce other pancreatic hormones (insulin, glucagon, somatostatin) at any time during development. Date et al. [11] presented data indicating that ghrelin is co-localised with glucagon in adult human and rat pancreas, whereas results from Volante et al. [12] indicated that ghrelin is co-localised with insulin in human. We were not able to confirm either of these results; instead, our data indicate that through to adult life ghrelin peptide production is confined to a distinct cell type $[4,5$, $13,21]$. The reason for this discrepancy is not clear. The absence of co-localisation of ghrelin with other hormones in humans is in contrast to the findings in mice by Prado et al. [5] and Heller et al. [9], where ghrelin and glucagon were found together early but not later in development. According to Polak et al. [22], most endocrine cells in the human pancreas are polyhormonal at about gestational week 8 , but lose this characteristic by week 9 . We cannot rule out the possibility that ghrelin co-localises with other hormones in stages of human pancreas development before gestational week 13 .

Third, we studied the production of some critical transcription factors in epsilon cells. PAX6 was not coproduced with ghrelin during development. This finding corresponds closely with the results in the mouse of Heller et al. [9], who demonstrated that epsilon cell genesis is not under PAX6 control, but is antagonised by PAX6 transcription factor. This line of evidence, together with the finding that epsilon cells do not co-produce glucagon during development, indicates that alpha and epsilon cells represent distinct endocrine cell types subjected to different regulatory signals. NKX6-1 was also not co-produced with ghrelin during development, while all epsilon cells coproduced NKX2-2. Consistent with our results, one study found that there was no observable modification of ghrelin cells in the islets of $N k \times 6-1$ knockout mouse [5]. The role of NKX2-2 appears to be more complex. In fact, $N k x 2-2$ [5] plays a key role in determining fate of the ghrelin cells by endocrine precursors in the mouse, since its ablation promotes a striking augmentation of epsilon cells [5, 8]. Together, the results in mutant mice and our evidence of NKX2-2 and ghrelin co-production in humans suggests that NKX2-2 may not be necessary to specify epsilon cells, but, being co-produced in the same cell type, may play a role in determining the transition of those cells into beta cell-type cells. Finally, all epsilon cells co-produced ISL1, a transcription factor required for development of the mesenchyme of the dorsal pancreatic bud and also for differentiation of the dorsal pancreatic epithelium into endocrine cells [23, 24].

Fourth, and for the first time, we estimated the epsilon cell mass in human adult pancreas (about $0.13 \mathrm{~g}$ ) and showed a significant inverse correlation of epsilon cell mass with BMI. The estimate is based upon relative volume calculations in a small portion of pancreas and should therefore be considered preliminary. Moreover, the range of the donors' BMI was rather narrow and the mean was at the higher end of what is normal or even above the limit for being overweight. Nevertheless, the relationship with BMI is consistent with reports of an inverse correlation between plasma ghrelin and BMI $[25,26]$.

Little is known about the role of ghrelin within the pancreas, but the hypothesis that ghrelin could play a paracrine/autocrine role in the regulation of beta cell survival and function [27] appears reasonable. The production of ghrelin in a prominent endocrine cell population in the fetal pancreas suggests a potential role in islet development. Interestingly, in this context, ghrelin has recently been reported to promote proliferation and cell growth, and also to inhibit apoptosis of pancreatic beta cells and human islets [27, 28]. Therefore, one function of ghrelin in the developing pancreas could be to promote cell growth and maturation locally.

An insulinostatic function of endogenous ghrelin within islets has been suggested [13, 15, 17, 29-31]. It was also recently shown to exert inhibitory effects on expression and production of inflammatory cytokines [32] and to attenuate the development of acute pancreatitis in rats by reducing inflammatory infiltrates of pancreatic tissues [33]. On this basis, we can speculate that the loss of epsilon cell mass associated with increased BMI could produce increased insulin secretion, but also an enhanced susceptibility to apoptosis and inflammation damage in pancreatic islets.

In conclusion, we investigated the endocrine mass during human pancreas development, with a special emphasis on the dynamics of changes in epsilon cells. We were able to show that large numbers of epsilon cells are present in human pancreas during fetal life and that the number and localisation of these cells is developmentally regulated. Epsilon cells were monohormonal and co-produced NKX2-2 and ISL1, but not NKS6-1 and PAX6. The exact role of ghrelin in endocrine pancreas maturation during fetal life and in pancreas reorganisation in adulthood is still unknown, but results obtained in our study suggest a significant impact of epsilon cells in early islet biology.

Acknowledgements This work was supported by Telethon Italy and the Juvenile Diabetes Research Foundation (JT01Y01), by the European Commission FP7 (DIAPREPP, HEALTH-F2-2008- 
202013), and by awards from Fondazione Cariplo (2007-5165) and Fondazione Siemens Italia (Milan, Italy). Part of this study will be incorporated into the $\mathrm{PhD}$ thesis of K. M. Andralojc.

Duality of interest The authors declare that there is no duality of interest associated with this manuscript.

\section{References}

1. Edlund H (2001) Developmental biology of the pancreas. Diabetes 50(Suppl 1):S5-S9

2. Cabrera O, Berman DM, Kenyon NS, Ricordi C, Berggren PO, Caicedo A (2006) The unique cytoarchitecture of human pancreatic islets has implications for islet cell function. Proc Natl Acad Sci U S A 103:2334-2339

3. Brissova M, Fowler MJ, Nicholson WE et al (2005) Assessment of human pancreatic islet architecture and composition by laser scanning confocal microscopy. J Histochem Cytochem 53:1087-1097

4. Wierup N, Svensson H, Mulder H, Sundler F (2002) The ghrelin cell: a novel developmentally regulated islet cell in the human pancreas. Regul Pept 107:63-69

5. Prado CL, Pugh-Bernard AE, Elghazi L, Sosa-Pineda B, Sussel L (2004) Ghrelin cells replace insulin-producing beta cells in two mouse models of pancreas development. Proc Natl Acad Sci U S A 101:2924-2929

6. Jensen J (2004) Gene regulatory factors in pancreatic development. Dev Dyn 229:176-200

7. Chanoine JP, Wong AC (2004) Ghrelin gene expression is markedly higher in foetal pancreas compared with foetal stomach: effect of maternal fasting. Endocrinology 145:3813-3820

8. Chao CS, Loomis ZL, Lee JE, Sussel L (2007) Genetic identification of a novel NeuroD1 function in the early differentiation of islet alpha, PP and epsilon cells. Dev Biol 312:523-532

9. Heller RS, Jenny M, Collombat $P$ et al (2005) Genetic determinants of pancreatic epsilon-cell development. Dev Biol 286:217-224

10. Wang Q, Elghazi L, Martin S et al (2008) Ghrelin is a novel target of Pax4 in endocrine progenitors of the pancreas and duodenum. Dev Dyn 237:51-61

11. Date Y, Nakazato M, Hashiguchi S et al (2002) Ghrelin is present in pancreatic alpha-cells of humans and rats and stimulates insulin secretion. Diabetes 51:124-129

12. Volante M, Allia E, Gugliotta P et al (2002) Expression of ghrelin and of the GH secretagogue receptor by pancreatic islet cells and related endocrine tumors. J Clin Endocrinol Metab 87:1300-1308

13. Wierup N, Yang S, McEvilly RJ, Mulder H, Sundler F (2004) Ghrelin is expressed in a novel endocrine cell type in developing rat islets and inhibits insulin secretion from INS-1 (832/13) cells. J Histochem Cytochem 52:301-310

14. Wierup N, Sundler F (2005) Ultrastructure of islet ghrelin cells in the human fetus. Cell Tissue Res 319:423-428

15. Dezaki K, Sone H, Koizumi M et al (2006) Blockade of pancreatic islet-derived ghrelin enhances insulin secretion to prevent high-fat diet-induced glucose intolerance. Diabetes 55:3486-3493

16. Sun Y, Asnicar M, Saha PK, Chan L, Smith RG (2006) Ablation of ghrelin improves the diabetic but not obese phenotype of ob/ob mice. Cell Metab 3:379-386

17. Dezaki K, Hosoda H, Kakei M et al (2004) Endogenous ghrelin in pancreatic islets restricts insulin release by attenuating $\mathrm{Ca}^{2+}$ signaling in beta-cells: implication in the glycemic control in rodents. Diabetes 53:3142-3151

18. Piper K, Brickwood S, Turnpenny LW et al (2004) Beta cell differentiation during early human pancreas development. J Endocrinol 181:11-23

19. Richardson MK, Hanken J, Gooneratne ML et al (1997) There is no highly conserved embryonic stage in the vertebrates: implications for current theories of evolution and development. Anat Embryol (Berl) 196:91-106

20. Butler AE, Janson J, Bonner-Weir S, Ritzel R, Rizza RA, Butler PC (2003) Beta-cell deficit and increased beta-cell apoptosis in humans with type 2 diabetes. Diabetes 52:102-110

21. D'Amour KA, Bang AG, Eliazer S et al (2006) Production of pancreatic hormone-expressing endocrine cells from human embryonic stem cells. Nat Biotechnol 24:1392-1401

22. Polak M, Bouchareb-Banaei L, Scharfmann R, Czernichow P (2000) Early pattern of differentiation in the human pancreas. Diabetes 49:225-232

23. Habener JF, Kemp DM, Thomas MK (2005) Minireview: transcriptional regulation in pancreatic development. Endocrinology 146:1025-1034

24. Ahlgren U, Pfaff SL, Jessell TM, Edlund T, Edlund H (1997) Independent requirement for ISL1 in formation of pancreatic mesenchyme and islet cells. Nature 385:257-260

25. Purnell JQ, Weigle DS, Breen P, Cummings DE (2003) Ghrelin levels correlate with insulin levels, insulin resistance, and highdensity lipoprotein cholesterol, but not with gender, menopausal status, or cortisol levels in humans. J Clin Endocrinol Metab 88:5747-5752

26. Monti V, Carlson JJ, Hunt SC, Adams TD (2006) Relationship of ghrelin and leptin hormones with body mass index and waist circumference in a random sample of adults. J Am Diet Assoc 106:822-828

27. Granata R, Settanni F, Biancone L et al (2007) Acylated and unacylated ghrelin promote proliferation and inhibit apoptosis of pancreatic beta-cells and human islets: involvement of $3^{\prime}, 5^{\prime}$-cyclic adenosine monophosphate/protein kinase A, extracellular signalregulated kinase $1 / 2$, and phosphatidyl inositol 3-Kinase/Akt signaling. Endocrinology 148:512-529

28. Irako T, Akamizu T, Hosoda $H$ et al (2006) Ghrelin prevents development of diabetes at adult age in streptozotocin-treated newborn rats. Diabetologia 49:1264-1273

29. Broglio F, Arvat E, Benso A et al (2001) Ghrelin, a natural GH secretagogue produced by the stomach, induces hyperglycemia and reduces insulin secretion in humans. J Clin Endocrinol Metab 86:5083-5086

30. Egido EM, Rodriguez-Gallardo J, Silvestre RA, Marco J (2002) Inhibitory effect of ghrelin on insulin and pancreatic somatostatin secretion. Eur J Endocrinol 146:241-244

31. Colombo M, Gregersen S, Xiao J, Hermansen K (2003) Effects of ghrelin and other neuropeptides (CART, $\mathrm{MCH}$, orexin A and $\mathrm{B}$, and GLP-1) on the release of insulin from isolated rat islets. Pancreas 27:161-166

32. Dixit VD, Schaffer EM, Pyle RS et al (2004) Ghrelin inhibits leptin- and activation-induced proinflammatory cytokine expression by human monocytes and $\mathrm{T}$ cells. J Clin Invest 114 : $57-66$

33. Dembinski A, Warzecha Z, Ceranowicz P et al (2003) Ghrelin attenuates the development of acute pancreatitis in rat. J Physiol Pharmacol 54:561-573 